\title{
Cidades brasileiras: entre valores e narrativas do urbanismo
}

\author{
Brazilian cities: between values and narratives of urbanism
}

Raíssa de Keller e Costa [a] [D, Vanessa Taveira de Souza [a] [D]

[a] Universidade Federal de Minas Gerais (UFMG), Programa de Pós-graduação Interdisciplinar em Ambiente Construído e Patrimônio Sustentável, Belo Horizonte, MG, Brasil

Como citar: Costa, R. K., \& Souza, V. T. (2021). Cidades brasileiras: entre valores e narrativas do urbanismo. urbe. Revista Brasileira de Gestão Urbana, v.13, e20200413. https://doi.org/10.1590/2175-3369.013.20200413

\section{Resumo}

As antigas cidades brasileiras, constituídas no período colonial, possuem espaços urbanos com características vinculadas às tradições urbanas portuguesas, mas ainda assim, possibilitam diferentes leituras e interpretações pelas suas singularidades relacionadas à localização no país, especialmente no interior e no litoral. Ao longo do século XX, essas singularidades favoreceram a formulação de diferentes narrativas sobre essas cidades, com publicações que nem sempre consideraram tais características urbanas a partir de diferentes olhares, atribuindo valores negativos e positivos a elas. Para demonstrar o processo epistemológico de construção dessas narrativas, aponta-se alguns marcos temporais, como 1930, 1960 e 2000. Esses marcos foram estabelecidos, para fins desse estudo, para nortear os contextos dessas narrativas e os valores envolvidos, com base em Boaventura de Souza Santos e suas contribuições sobre senso comum e ciência. A partir de pesquisa bibliográfica e documental, foram apontados exemplos de algumas cidades litorâneas e estudo de caso na cidade interiorana de Ouro Preto, Minas Gerais, pelas formas como são apresentados os processos de constituição de seus espaços na bibliografia. Como resultado, esse artigo demonstra como os diferentes valores relacionados ao contexto histórico das antigas cidades brasileiras se transpuseram entre o senso comum e a ciência por meio de algumas narrativas predominantes.

Palavras-chave: Ciência. Senso comum. Tradição. Urbanismo. Cidades brasileiras.

\section{Abstract}

The old Brazilian cities, constituted in the colonial period, have urban spaces with characteristics linked to Portuguese urban traditions, but still, they allow different readings and interpretations due to their singularities related to the location in the country, especially between interior and coast. Throughout the 20th century, these singularities favored the formulation of different narratives about these cities, with publications that did not always consider such urban characteristics from different perspectives, attributing negative and positive values to them. In order to demonstrate the epistemological process of construction of these narratives, some temporal milestones are pointed out, such as 1930,1960 and 2000. These milestones were established, for the purposes of

RKC é turismóloga, mestre em Ambiente Construído e Patrimônio Sustentável, e-mail: raissakc@yahoo.com.br VTS é arquiteta e urbanista, mestre em Artes, e-mail: vanessaarquitetarestauradora@gmail.com 
this study, to guide the contexts of these narratives and the values involved, based on Boaventura de Souza Santos and his contributions on common sense and science. From bibliographic and documentary research, examples of some coastal cities and case studies in the interior city of Ouro Preto, Minas Gerais, were pointed out, due to the ways in which the processes of constitution of their spaces are presented in the bibliography. As a result, this article demonstrates how the different values related to the historical context of the old Brazilian cities were transposed between common sense and science through some predominant narratives.

Keywords: Science. Common sense. Tradition. Urbanism. Brazilian cities.

\section{Introdução}

No Brasil, as cidades construídas no período colonial estão relacionadas com a história e o passado do país, se apresentando como símbolos de um período, representações de um contexto. Da estrutura urbana dessas antigas cidades coloniais brasileiras, nem tudo se conservou tal como era naquele período, já que a cidade acompanha o ritmo de cada tempo e, com ele, a dinâmica social. Mas o debate nessa relação com o passado favorece diferentes leituras daqueles espaços urbanos, bem como de seus aspectos socioculturais. É nessa direção que foi elaborada a proposta para esse estudo, do entendimento das narrativas sobre esses espaços urbanos das antigas cidades brasileiras para a compreensão dos valores envolvidos em cada contexto, tendo como pano de fundo a relação entre senso comum e ciência a partir das reflexões de Boaventura de Souza Santos (1989).

Há uma percepção no senso comum de que essas antigas cidades brasileiras não teriam sido planejadas devido às características dos espaços onde elas foram inseridas. Partindo desse pressuposto, é importante buscar compreender as bases desse pensamento coletivo comum. De acordo com Boaventura de Souza Santos (1989, p. 34), "o senso comum é um conhecimento evidente que pensa o que existe tal como existe e cuja função é reconciliar a todo custo a consciência comum consigo própria". Considerando que elas apresentam estruturas urbanas que remetem ao período colonial, bem diferentes das cidades consideradas modernas, a transformação do espaço em vilas e cidades se deu sob diferentes perspectivas, numa relação com a tradição urbana de Portugal. Assim, a cidade de Ouro Preto em Minas Gerais, por se apresentar com relevo acidentado, com construções que sobrevivem ao tempo em técnicas construtivas tradicionais, igrejas monumentais típicas daquele período e outros monumentos vinculados aos poderes, sem falar nas ruas estreitas e sinuosas, parecem se apresentar como evidência dessa consciência comum de que fala Santos (1989), para o autor, "um pensamento necessariamente conservador e fixista", e que por vezes, foi amparado pela ciência.

Um exemplo dessas narrativas com críticas ao desenvolvimento do espaço urbano das antigas cidades brasileiras, no começo do século XIX, é a do historiador Sérgio Buarque de Holanda no clássico "Raízes do Brasil" de 1936, que evidenciou o relevo inclinado da cidade de Salvador como "uma colina escarpada" e considerou a escolha do lugar, pelos portugueses, lamentável (Holanda, 1995, p. 110). Cabe compreender que as referências para o planejamento urbano dessa versão historiográfica são simetrias e padrões muito presentes na Europa e nas colônias espanholas.

Por outro lado, as pesquisas recentes mostram outras perspectivas, ao considerarem novos fatores relacionados à tradição urbanista portuguesa. Sendo este um constante exercício de se afastar das impressões lógicas, instantâneas e de senso comum, a demanda por novas pesquisas se faz essencial para se aproximar de um entendimento que leve em conta novos aspectos e interpretações.

Entre o pensamento que caracteriza o senso comum e a ciência, há que se considerar os desdobramentos na produção do conhecimento científico a partir do confronto entre o senso comum e a ciência, propostos por Santos (1989). Em que momento a ciência (História e Urbanismo) passou a considerar o planejamento urbano das antigas cidades coloniais brasileiras? O que caracteriza, por essas ciências, a abordagem acerca desse planejamento? Assim, espera-se contribuir com as reflexões sobre esses processos de construção do conhecimento com esse estudo de caso, acerca da história dos espaços urbanos 
da antiga cidade colonial de Ouro Preto. Esse estudo é fruto de discussões e orientações em disciplina de doutorado, baseadas na interdisciplinaridade, mediados pela Professora Doutora Beatriz D’Alencar Couto.

\section{Planejamento das cidades coloniais brasileiras: entre o senso comum e a ciência sob a ótica de Boaventura de Sousa Santos}

A estrutura urbana das antigas cidades coloniais brasileiras possibilita pensar o passado e as relações com os espaços cujas escolhas deram origem a cidades que, atualmente, ocupam lugares de destaque no cenário nacional enquanto exemplares da cultura e atrativos turísticos que se baseiam nesse ideal de patrimônio.

No que tange a essas estruturas urbanas, altamente valorizadas na contemporaneidade por suas características coloniais, acredita-se que havia um entendimento no senso comum com relação à falta de planejamento de muitas delas. Se atribui a essa perspectiva, com frequência na bibliografia, a questão do relevo - a princípio inapropriado para a construção de cidades, e a disposição das edificações ao longo do relevo acidentado, construções e ruas consideradas improvisadas, por exemplo em Smith (2012) e Holanda (1995), publicados respectivamente em 1956 e 1936. Por outro lado, há também na bibliografia recorrentes discussões que refutam essa visão das cidades, como aponta Bicalho (1998), Delson (1997), Pereira (2000). Assim, identificam-se duas narrativas com relação à urbanização das antigas cidades coloniais brasileiras: a primeira delas considera que muitas cidades foram instaladas em território inapropriado por improviso, sendo, portanto, alvos de uma adjetivação negativa; e a segunda considera que cidades coloniais consideradas planejadas eram as que possuíam traçados geométricos e simétricos, essas vinculadas a adjetivações positivas - narrativas instituídas no período entre 1930 e 2000. Independentemente das narrativas, todas essas cidades são espaços urbanos de valor histórico e artístico da sociedade, cujos processos de construção se consolidaram ao longo do tempo no discurso do passado nacional. Por isso, não cabe para fins deste estudo tomar partido das narrativas, mas compreender a historicidade delas e suas problematizações.

Observa-se, na sobreposição dessas duas narrativas, uma ruptura na perspectiva epistemológica do senso comum para o conhecimento científico, do conhecimento científico incorporado pelo senso comum ao científico da ciência pós-moderna, com base em Boaventura de Sousa Santos (1989). Mas como Santos explica as rupturas? E de que forma elas são capazes de demonstrar a importância ou não das narrativas populares do urbanismo do período colonial?

Em "Ciência e Senso comum", Santos (1989) aponta o surgimento da ciência pós-moderna com base no senso comum, considerando o que ele denomina de dupla ruptura: a primeira quando a ciência rompe com o senso comum; e a segunda quando o senso comum é incorporado na ciência e se transforma. Essas reflexões inserem-se no contexto de uma crise da ciência, que é também uma crise da epistemologia, compreendendo que esse paradigma dogmático é insuficiente e requer substituição para compreender toda a complexidade das disciplinas.

No contexto do urbanismo das cidades coloniais, a percepção de que não houve planejamento parece fundamentar-se no senso comum. "O senso comum, o conhecimento vulgar, a sociologia espontânea, a experiência imediata, tudo isto são opiniões, formas de conhecimento falso com que é preciso romper para que se torne possível o conhecimento científico, racional e válido" (Santos, 1989, p. 33). Mas quais as bases para esse entendimento? Na América Latina, o ideal de cidade colonial defendido por historiadores em sala de aula seriam as cidades planificadas no Novo Mundo construídas pelos espanhóis, ou seja, a América Espanhola.

Tornou-se quase axiomático falar entusiasticamente das ruas admiravelmente traçadas em cruz e das praças centrais em quadrado que caracterizavam as aglomerações urbanas da América espanhola, chamando-se a atenção do estudante para a legislação de planejamento bem elaborada que acompanhava a criação dessas comunidades (Delson, 1997, p. 1). 
Em "O mito da cidade brasileira sem planificação", Roberta Marx Delson aponta que a ideia de cidades não planejadas só foi contestada no final de década de 1950, com a criação de Brasília, "quando anunciou uma nova era de consciência urbana no Brasil" (Delson, 1997, p. 1). Delson apresenta as barreiras em sua pesquisa e desenvolvimento do estudo, já que, segundo ela, historiadores, arquitetos e geógrafos tendiam a descartar o assunto. Essas barreiras podem ser compreendidas como uma ruptura epistemológica com base em Santos (1989), já que a proposta é desmistificar uma ideia amplamente defendida pela ciência. A autora parece apontar que essas ideias partiram do senso comum e se transformaram em conhecimento científico, quando utiliza de termos como "típica das afirmações vulgares encontradiças sobre esse tema" e ainda "opinião superficial" para tratar dos historiadores que defendem a narrativa das construções espontâneas. Assim, trazendo para as rupturas de Santos (1989), trata-se do primeiro de três atos epistemológicos fundamentais: a ruptura, a construção e a constatação.

A construção científica proposta por autores como Delson (1997) ergue-se contra um conhecimento anterior, prática que Santos (1989) aponta como tarefa difícil nas construções em geral. Esse conhecimento anterior, como defendido pelo intelectual brasileiro Sérgio Buarque de Holanda, publicado em 1936, apresenta a ideia de que "a cidade que os portugueses construíram na América não é um produto mental, não chega a contradizer o quadro da natureza, e sua silhueta se enlaça na linha da paisagem" (Holanda, 1995, p. 110). Compreendendo que as bases dessas assertivas estariam pautadas nos valores existentes no começo do século XX, no que tange à modernização das cidades, é possível estabelecer a relação que Holanda fez com o senso comum.

As antigas cidades coloniais brasileiras, no final do século XIX e princípio do século XX, estiveram ameaçadas no contexto do progresso e do desenvolvimento no sentido de que não tinham a oferecer os padrões que a modernidade impunha, o crescimento que se apresentava como tendência não poderia ser abarcado por elas. Desse movimento ocorreram várias mudanças consideradas significativas na historiografia do país, por exemplo, a transferência da capital de Minas Gerais da cidade de Ouro Preto para a nova cidade construída para atender a novas demandas, Belo Horizonte. Soma-se a isso o abandono das antigas cidades em termos de conservação e investimentos em seus bens culturais, bem como Tiradentes e Ouro Preto, como cidades consideradas pequenas e muito menos atrativas que as cidades novas, no que tange à progresso e economia.

Com base em situações como essas, que estavam em discussão nas primeiras décadas do século XX, é que se pode compreender que o estudo publicado por Holanda se encontra nessa relação com o senso comum, e de acordo com Santos:

Daí que não seja fácil aos cientistas manter sempre uma relação realista com a sua prática científica (a filosofia diurna) e cedam, por vezes, à tentação de aceitar o conforto de ideias vulgares, por vezes recobertas de jargão filosófico, preconceitos idealistas, noções pseudo-científicas, enfim um conjunto de erros tenazes que lhes é muitas vezes proposto pelas várias filosofias das ciências em uso (a filosofia noturna dos cientistas) (Santos, 1989, p. 35).

Cabe compreender, para além disso, que as referências para o planejamento urbano dessa versão historiográfica são simetrias e padrões muito presentes na Europa e nas colônias espanholas. Curioso notar, que reconhecem a organização em torno das igrejas, cujas localizações eram em lugares mais altos e de grande visibilidade, o que indiretamente pressupõe uma lógica e uma organização. 0 texto de Holanda parece, assim, ter seu enfoque nas questões políticas que determinaram as construções bem como para o modelo de colonização, ao contrapor as cidades da colonização espanhola e portuguesa na América, elogiando as primeiras e atribuindo como negativas as segundas. Em todo caso, André Luiz Tavares Pereira, em 2000, confirma a predominância dessa narrativa ao dizer que "os estudos sobre a história do urbanismo brasileiro e das suas cidades pagam tributo a um modelo estabelecido por Sérgio Buarque de Holanda e que até hoje é corrente entre os pesquisadores brasileiros" (Pereira, 2000, p. 26).

A permanência dessa narrativa parece ser um fator de tradição, com base em Santos (1989), ao tratar da crise final do paradigma da ciência moderna, em que recomenda que a epistemologia não seja 
abandonada pois é necessária para pensar a próxima revolução científica, o reencontro da ciência com o senso comum, o progresso da "racionalização do mundo". Ele aponta a relação entre o senso comum e a ascensão do poder da burguesia, tendo sido a sua valorização filosófica relacionada a esse projeto político, assim explica-se a sua desvalorização. Nessa relação com a sociedade de classes, Santos (1989) coloca a necessidade de assumir o viés conservador que "naturaliza as desigualdades" sem opô-las, tendo em vista que "o senso comum é o modo como os grupos ou classes subordinadas vivem a sua subordinação", vivência com muitos sentidos de resistência. Além disso, "a própria ciência vem reconhecendo que há preconceitos e preconceitos e que, por isso, é simplista avaliá-los negativamente” (Santos, 1989, p. 40-41).

Ao considerar os estudos do urbanismo no Brasil é possível relacionar a estrutura urbana das antigas cidades coloniais com seus elementos, demarcando as paisagens e estabelecendo o poder, bem como as posições das igrejas. A influência da religião católica nas colônias, para além dos monumentos eclesiásticos, que se destacam nas paisagens por sua ampla visibilidade, impactou também a organização e expansão das edificações e das ruas na constituição das vilas, privilegiando questões relacionadas às classes dominantes. Esses bens culturais podem ser considerados símbolos de um período, devidamente escolhidos como tal para permanência no imaginário coletivo.

Como já dizia Bourdieu (1989), grosso modo, os símbolos são elementos de coesão social; as produções simbólicas têm relações profundas com os interesses da classe dominante, da luta pela hierarquia, sem deixar de considerar a importância das classes menos favorecidas no processo, já que na luta simbólica "ao servirem os seus interesses na luta interna do campo de produção (e só nesta medida) que os produtores servem aos interesses dos grupos exteriores ao campo de produção" (Bourdieu, 1989, p. 12). Assim, os símbolos de um passado colonial no Brasil, quando legitimados através da patrimonialização das edificações produzidas pelo Estado e pela Igreja no período colonial, podem ser lidos como uma produção da classe dominante, atrelado ao poder do capital econômico com intuito de impor a legitimidade de seu domínio e a ideia de nação.

[...] a cultura que une (intermediário de comunicação) é também a cultura que separa (instrumento de distinção) e que legitima as distinções compelindo todas as culturas (designadas como subculturas) a definirem-se pela sua distância em relação à cultura dominante" (Bourdieu, 1989, p. 11).

Em se tratando das instituições religiosas, tem-se como exemplo, a Constituição Primeira do Arcebispado da Bahia publicada em 1707, de cunho pedagógico e religioso, e adaptado às condições da colônia. 0 Livro Quarto, título XVI, da Constituição Primeira do Arcebispado da Bahia (1853, p. 251) trata, por exemplo, da preservação do patrimônio da igreja e das sepulturas; a começar pela determinação de que qualquer construção de Igreja, capela ou mosteiro deveria ser autorizada pelo Arcebispado, bem como a necessidade de licença para a realização das missas. Em seguida, destacam-se as regulações sobre as reparações, quando necessárias (Constituição primeira do Arcebispado da Bahia, 1853, p. 252); ou, ainda, a proibição de que as igrejas e seus adros sirvam de castelos ou fortalezas, ou coisas semelhantes, "As Igrejas, que são Casas de paz, (1) e Templos do Rei pacifico, (2) edificadas para nellas com socego, e quietação se louvar a Deos, e celebrarem os Officios Divinos, não devem servir de Castellos, nem de se exercitar nellas a arte, e cousas militares" (Constituição primeira do Arcebispado da Bahia, 1853, p. 270).

Conforme o direito Canonico, (1) as Igrejas se devem fundar, e edificar em lugares decentes, e acomodados, pelo que mandamos, que havendo-se de edificar de novo alguma Igreja parochial em nosso Arcebispado, se edifique em sitio alto, e lugar decente, livre da humidade, e desviado, quanto for possivel, de lugares immundos, e sordidos, e de casas particulares, e de outras paredes, em distancia que possão andar as Procissões (2) ao redor dellas, e que se faça em tal proporção, que não sómente seja capaz dos freguezes todos, mas ainda de mais gente de fôra, quando concorrer ás festas, e se edifique em lugar povoado, (3) onde estiver o maior número dos fregueses. E quando se houver de fazer, (4) será com licença nossa: e feita vestoria, iremos primeiro, ou outra pessoa de nosso mando, 
levantar Cruz no lugar onde houver de estar a Capella maior, e demarcará o ambito da Igreja, e adro della (Constituição primeira do Arcebispado da Bahia, 1853, p. 252-253).

Essa Constituição prevaleceu na colônia portuguesa por mais de um século, válida em todo o território até a instalação do Regime Imperial; uma nova legislação eclesiástica só foi elaborada no Concílio Latinoamericano de 1899-1900. Regulamentos como esse, de alto impacto e poder no Brasil, parecem corroborar com a versão historiográfica que entende que a urbanização das antigas cidades foi pensada, no entanto, os planos não diziam respeito a geometrias e padrões simétricos, mas a relações de poder, relações com a paisagem.

Com relação aos estudos de morfologia urbana, sobre essa lógica de distribuição espacial desses símbolos de poder em lugares estratégicos e de destaque na paisagem, "Trata-se, efetivamente, do papel estruturador do espaço desempenhado pelas duas instituições mais características da dominação ideológica - política e religiosa - dos períodos colonial e imperial: o Estado e a Igreja Católica" (Villaschi, 2014, p. 83). Esses símbolos se traduziram principalmente em exemplares arquitetônicos únicos e monumentais delineando a paisagem como ferramenta de regulação social, (Villaschi, 2014).

Nessas diferentes perspectivas e nessas relações de poder implícitas até mesmo nos paradigmas da ciência moderna, é importante considerar o que Santos (1989) compreende como dupla ruptura, que se trata de uma transformação tanto do senso comum como da ciência. "Enquanto a primeira ruptura é imprescindível para constituir a ciência, mas deixa o senso comum tal como estava antes dela, a segunda ruptura transforma o senso comum com base na ciência constituída e no mesmo processo transforma a ciência" (Santos, 1989, p. 45). E propõe que na "dupla transformação pretende-se um senso comum esclarecido e uma ciência prudente", um "saber prático", possível atualmente pelo avanço da comunicação atribuído à ciência moderna.

Mediante às explanações dos autores apontados, compreende-se que até a década de 1950, os debates foram imprescindíveis para constituir a ciência da historiografia do urbanismo nas cidades coloniais brasileiras, mas ainda não significou uma transformação da ciência. Ou seja, o posicionamento de Holanda deu voz ao senso comum, e é visto como controverso por se tratar de um pesquisador. No entanto, as narrativas após a década de 1960, que contestam Holanda e outros, parecem se traduzir em uma valorização da ciência acima do senso comum, como a oposição luz e trevas que Santos (1989) coloca em seu texto e que não recomenda. Já os estudos do século XXI parecem se aproximar da transformação da ciência, mais próximo do saber prático de Santos e que ainda há que avançar. Afinal, entender os contextos das diferentes narrativas permite que se identifique os valores de cada tempo, as discussões que permearam as publicações e influenciaram os autores, favorecendo assim o debate para um conhecimento mais abrangente e interdisciplinar. Longe de esgotar o assunto, cabível em pesquisas mais aprofundadas, esperase demonstrar a relação da paisagem das antigas cidades coloniais com o urbanismo, com enfoque na cidade de Ouro Preto em Minas Gerais.

\section{Tradições urbanas portuguesas e a fundação de cidades brasileiras}

Compreendendo que as antigas cidades coloniais brasileiras possuem características bem específicas no que tange ao planejamento urbano e desenvolvimento, espera-se contribuir para o entendimento da historicidade de algumas delas, tomando como exemplos aspectos das cidades de Olinda, Mariana, Salvador, e como estudo de caso, Ouro Preto (MG). A escolha dessa cidade se deve à tentativa de demonstrar, nela, as duas narrativas apontadas anteriormente, a contraposição entre improviso e planejamento, que, ao que tudo indica, estão envoltas por determinados valores culturais, históricos, artísticos e sociais.

Para a fundação efetiva de cidades no litoral do Brasil utilizou-se da tradição portuguesa de modelos e expressões urbanas importantes de serem aqui compartilhadas. Correia (2020) argumenta que os portugueses prezavam pela: escolha de um sítio alto para implantação das cidades com "bons ares", de preferência separado das baixas áreas portuárias; a previsão de instalações religiosas com cercas em suas 
periferias; e a implantação de edificações de defesa militar em suas costas marítimas. Além disso, no miolo dessas cidades, pretendiam sempre que possível optar por linearidades em seus traçados através da implantação de linhas paralelas às costas marítimas e travessas perpendiculares a elas. Muitas vezes essas linhas, quando cruzadas, foram também associadas à implantação de malhas ortogonais, formando os quarteirões. A primeira cidade planejada pelos portugueses, nesse caso por Duarte Coelho, foi Olinda (1535) e essa seguia todas essas premissas urbanísticas.

A segunda cidade planejada pelos portugueses foi Salvador (1549). Nesse caso, segundo Felipe Eduardo Moreau (2011), o traçado urbano tem autoria do Miguel de Arruda, mestre-arquiteto e engenheiro-chefe das fortificações do Reino de Portugal, e o administrador da obra foi Luiz Dias. Esses escolheram o melhor local para implantação da cidade, ao meio da enseada na ampla colina que dominava a baía e consideraram o aporte de um porto natural na sua parte baixa. Registra-se que nesse sítio havia uma situação familiar para os portugueses, as existentes para as cidades de Lisboa e Porto em Portugal, que também possuem suas partes da cidade divididas em alta e baixa. Na parte alta de Salvador foram desenhados os principais edifícios institucionais e a maior parte das moradias, enquanto na parte baixa foram desenhados edifícios com funções portuárias e mercantis. Sua construção foi um marco da segunda fase de colonização portuguesa no Brasil, se estabelecendo uma capital na colônia com administração centralizada na Coroa portuguesa.

Houve uma definição pelos planejadores portugueses para Salvador do desenho de uma malha invertida e ortogonal, com a proposição de conjuntos de quarteirões quadrados e retangulares, com proporções diferentes, que foram adaptados à topografia do sítio alto e baixo destinado a capital (Moreau, 2011). Assim como a definição de ruas com hierarquias, locais livres para praças e largos (ex: Praça Principal, Largo da Ajuda, Largo da Porta de Santa Luzia, entre outros) e a implantação de edificações importantes de controle como a Casa de Câmara e Cadeia. Além disso, suas áreas limítrofes foram pensadas, assim como os locais periféricos, para implantação de instituições religiosas e suas cercas, e os locais de defesa, através da execução de fortificações, além das ligações entre parte alta e baixa da cidade, que também foram pontuadas. Depois, houve outras implantações pensadas para as cidades no litoral do Brasil, como as das cidades do Rio de Janeiro (1565), João Pessoa (1585), São Luís do Maranhão (1612), entre outras. Em todas elas verifica-se a influência das tradições urbanas portuguesas para a fundação de cidades brasileiras.

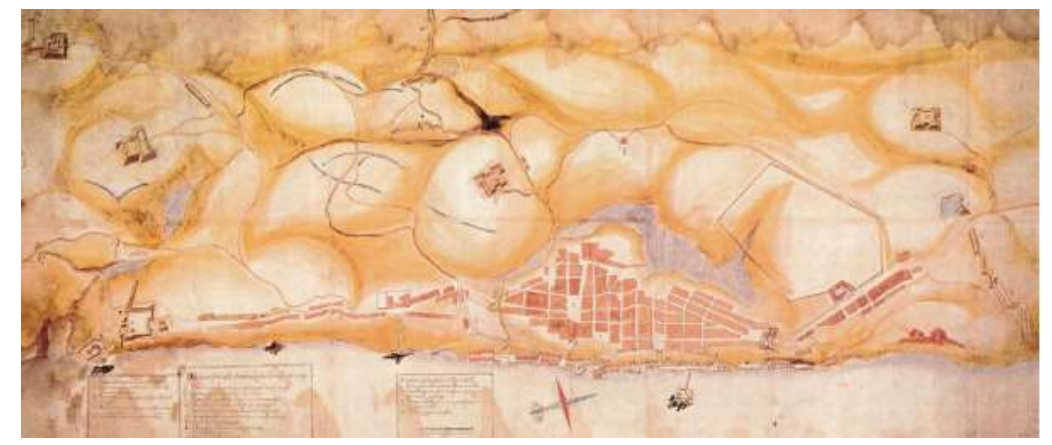

Figura 1 - A malha de Salvador no mapa de Haia (1638): já configurada nos anos de 1580. Fonte: Reis Fo, 2000, p. 32-4. In: Moreau, 2011.

0 planejamento de cidades pelos portugueses no interior do território brasileiro, estimuladas pela descoberta do ouro no século XVII em Minas Gerais, promoveu uma "corrida ao ouro" pelos colonos e estrangeiros. Consequentemente, estimulou um processo mais rápido (cerca de 50 anos) de planejamento urbano dessas cidades que as dos litorais, apresentando, assim, outros fatores relevantes para o seu entendimento. 0 primeiro deles é a relação dessas cidades com os rios e os morros; os rios porque foram os locais onde o ouro de aluvião foi encontrado, e os morros porque se constituíram nos principais locais de pousos das datas de terras estabelecidas pelo Reino de Portugal para a exploração mineral. Ressalta-se que, logo depois a relação com os morros foi novamente fortalecida, com a descoberta do ouro de filão, presente 
nas minas, que propiciou uma ocupação mais efetiva através da implantação de residências. Nesse modelo de ocupação, segundo Correia (2020), o desafio era vencer as cotas altimétricas promovendo arruamentos e condicionando lotes a eles. Além disso, também eram pensadas para essas cidades, nos locais altos, a instalação de Casas de Câmara e Cadeia, além de instituições religiosas, ambas associadas geralmente a largos e espaços livres em seu entorno, para acontecimentos sociais, como a procissão ou ordenação da legislação, nesse caso onde geralmente se encontrava também um pelourinho.

Seguindo esses processos, como exemplo, tem-se a cidade de Mariana e a antiga Vila Rica (atual Ouro Preto). A primeira sede do bispado em Minas Gerais, Mariana (1696), obteve um planejamento erudito de seu núcleo, ordenado por um plano urbano, que determinava sua instalação em local alto e longe das inundações do rio, além de propor linearidades em seu traçado. Evidencia-se, também, a atual cidade de Ouro Preto (1711) que, segundo Marina Salgado (2010), tem seu tecido estruturado pelo "caminho-tronco" que a atravessa de oeste a leste. Assim, suas vias extensas seguem paralelas a ele ou, em alguns casos, diagonais às curvas de nível presentes no terreno, sendo que algumas ruas - as mais curtas e com alta declividade - apresentam-se perpendiculares a essas curvas de nível e diagonais. Os lotes, em geral, possuem a testada com dimensões reduzidas, diferentemente do seu cumprimento extenso, o que conduz ao aparecimento de grandes áreas livres na sua porção posterior, sendo apropriadas muitas vezes para o uso de quintais. As edificações encontram-se implantadas na testada desses lotes, sem recuo frontal, e em grande parte, sem recuo lateral. Já as edificações religiosas fundadas por leigos das ordens terceiras, Irmandades e Confrarias em Minas Gerais foram implantadas em lotes destacados dentro desses arruamentos ou em morros altos no entorno das cidades. Isso demonstra que, diferentemente das instituições religiosas fundadas pelas ordens terceiras no litoral, as constituídas no interior, durante essa fase, teriam mais liberdade em seus projetos e edificações, devido a participação da população mineradora, responsável por sua construção e manutenção.

No mapa que apresenta a Vila Rica no século XVIII, é possível observar o caminho-tronco e a relação com os córregos, onde inicialmente foram construídas as moradias no movimento centrípeto, para que depois essas adentrassem o território, num movimento centrífugo.

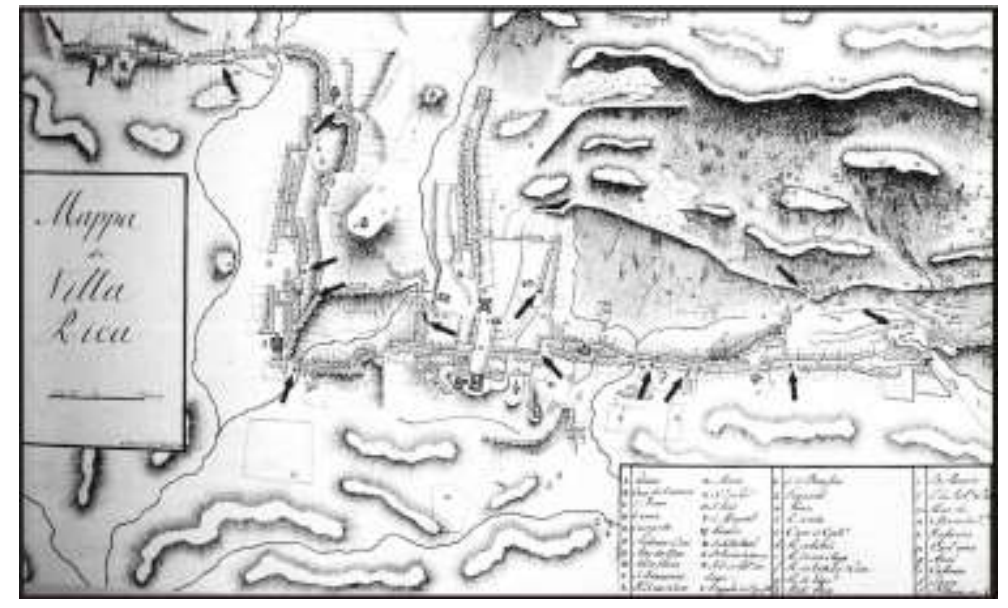

Figura 2 - Mapa de Vila Rica, no século XVIII. Caminho Tronco e praça principal da cidade com marcações em setas para a localização dos principais chafarizes. Fonte: Adaptação de FONSECA; PRADO FILHO (2004), de Acervo Histórico do Exército, de "Mappa de Villa Rica" (1785-1800).

Vila Rica (atual Ouro Preto) se formou através da junção dos arraiais de Antônio Dias, Ouro Preto, Padre Faria, Piedade e Cabeças e posteriormente aos arraiais de Santana, São Sebastião e São João. Para Salgado (2010), a elevação de arraiais embrionários à condição de Vila, como por exemplo Vila Rica, revela a intenção da Coroa Portuguesa de demarcar e fiscalizar todo o território da Capitania de Minas do Ouro (criada posteriormente também como forma de controle), instalando funcionários do Reino, impondo a ordem e a justiça, assim como a cobrança de tributos, reforçando o desenvolvimento de um processo intenso 
de civilidade. Uma diferença interessante entre as cidades fundadas no litoral e as do interior é de que nessas não eram edificadas fortificações militares e sim locais de controle de entrada e saída para fiscalização.

Para combater o contrabando do ouro e aumentar a arrecadação dos impostos pela Coroa Portuguesa, foi proibida a circulação de ouro em pó, e se estabeleceu que este deveria ser fundido e selado nas Casas de Fundição, que teriam sua criação proposta em 1719, em Vila Rica. Essas duas iniciativas seriam formas de controle e fiscalização nessa região. Depois, em um período de regulamentações urbanas baseadas nas Ordenações do Reino houve uma nova forma de regulamentação que, segundo Salgado (2010), se atentavam mais as questões relativas ao caráter social, como vizinhança e convivências do que aos termos espaciais, do traçado e parcelamento do solo. Como por exemplo, as características do afastamento dos arraiais, devido às concessões das datas de terras para exploração de ouro, que deviam ser implantadas com uma certa distância umas das outras para se evitar conflitos nas áreas de extração do ouro. Essa seria outra diferença em relação às cidades fundadas no litoral, onde as divisões de terras foram em grandes glebas. A Casa de Câmara, também implantada posteriormente, obteve um importante papel em medidas relativas a ocupação do solo urbano e às edificações, esse segundo momento marca a nova divisão de terras, que de datas passou para lotes.

Posteriormente, os arraiais que deram origem à cidade de Ouro Preto foram cornubados e a cidade cresceu devido a novos processos de adensamento, como os propiciados pela implantação da ferrovia e da Universidade Federal de Ouro Preto (UFOP). Mas ainda é possível identificar esse primeiro momento histórico em sua malha urbana através de uma análise de sua morfologia. Depois houve outras implantações pensadas para as cidades no interior do Brasil, como as das cidades de São João del Rei (1713), Tiradentes (1718), Diamantina (1831), entre outras. Nessas, também se verifica a influência das tradições urbanas portuguesas para a fundação de cidades brasileiras no período aurífero.

Contudo, tanto as cidades coloniais fixadas no litoral quanto as fixadas no interior do Brasil obtiveram influência em seus planejamentos nas tradições urbanas portuguesas, apesar de se verificar algumas adaptações em suas formas de desenho urbano. Isso está, muitas vezes, condicionado pelas diferenças e intenções pretendidas para os seus sítios, assim como por suas características topográficas e hidrográficas, as atividades econômicas e suas peculiaridades sociais e religiosas estabelecidas por suas diversas matrizes culturais. Sendo assim, Salvador e Ouro Preto, de forma ilustrativa e comparativa, demonstram essa influência de controle da Coroa Portuguesa sobre o território colonizado brasileiro, seus vários processos intencionais de concepção e transformadores de ocupação e substituição.

\section{Ouro Preto: valores e narrativas}

A cidade de Ouro Preto, em Minas Gerais, Brasil, é um espaço urbano de valor histórico e artístico representativo da sociedade brasileira, haja vista seus títulos e reconhecimentos dados através de sua patrimonialização, rendendo-lhe o título de Monumento Nacional numa iniciativa pioneira em 1933, tombamento pelo Serviço do Patrimônio Histórico e Artístico Nacional (SPHAN) em 1938, e ainda, o reconhecimento como patrimônio da humanidade em 1980. Todo esse pioneirismo da cidade, face aos processos de patrimonialização e políticas de preservação, contribuem para a valorização do passado colonial e da própria história da nação, consolidando a sua imagem ao longo do tempo.

A cidade se encontra à luz das discussões e pesquisas acerca de sua historicidade no cenário nacional e internacional - há algumas décadas, e um alto potencial para novos desdobramentos, tendo em vista o rico acervo documental gerado a partir de tamanha visibilidade da cidade desde o século XVIII e de novos olhares para o passado. Todas essas referências, que contribuem para pensar ou repensar o passado brasileiro sob a ótica da colonização evocam termos como "cidade monumento" ou "cidade patrimônio", numa relação com valores artísticos e tradicionais de representação. Motivadas por essas relações, esperase aqui apontar aspectos da cidade num recorte que relacione o urbanismo da cidade colonial, com aspectos socioculturais, que tenham contribuído para a construção desse espaço urbano, contrapondo com as 
narrativas apresentadas acerca do planejamento urbano, especialmente com relação aos valores que nortearam os contextos.

Para a compreensão dos valores relacionados ao espaço urbano da cidade, um dos marcos importantes na história é a transferência da capital mineira de Ouro Preto para Belo Horizonte - no final do século XIX, que precede a narrativa instituída por Holanda em 1936, tendo-a, provavelmente, influenciado. Para além das questões políticas relacionadas, que não cabem nesse estudo, serão considerados os valores que nortearam tais decisões, valores esses imbricados nas características do espaço urbano da cidade e na sociedade.

$\mathrm{Na}$ justificativa para a mudança da capital destaca-se que a cidade era vista como ultrapassada, decadente, desordenada, inapropriada para as necessidades de uma capital que se pretendia moderna pelos preceitos internacionais. Nesse momento da história do Brasil, década de 1890, ainda não havia essa valorização em torno dos bens culturais e símbolos do passado e por isso decisões como essa se baseavam apenas nas necessidades de modernização, desenvolvimento e progresso, como aponta Natal (2007). Essa imagem da cidade, naquele momento, estaria diretamente relacionada às características do seu espaço urbano, tendo em vista que os adjetivos empregados remetiam à sua estrutura antiga e considerada arcaica, colonial. Nessa direção, assim como os seus símbolos não eram considerados por seus valores históricos e artísticos, também não existia a valorização da estrutura urbana como um todo, apenas a necessidade de modernizá-la de acordo com a tendência.

Muito se discutiu a respeito da forma da cidade, especialmente quando a comunidade resistia à transferência da capital, encabeçando projetos de melhorias e buscando possibilidades para atender às exigências.

Para combater as ameaças que rondavam Ouro Preto, e preservar seu status de capital, as autoridades políticas ouropretanas cogitaram de modernizar a cidade como forma de manter sua centralidade política. Então, foi criada a Empresa de Melhoramentos da Capital, um projeto que visou à modernização de Ouro Preto. Esta modernização pressupunha o fim de sua imagem decaída de cidade colonial, e consistia em reformas e transformações que abrangeriam toda a malha urbana (Natal, 2007, p.4).

A perda da condição de capital mineira deixou, portanto, uma lacuna na vida de Ouro Preto, tendo em vista que as alterações na dinâmica da cidade foram substanciais com a transferência de várias atividades e instituições de poder e até mesmo de pessoas que seguiram o fluxo da modernidade, deixando para trás a velha cidade em busca de novas oportunidades, como aponta Villaschi (2014): "São dramáticos os relatos que se encontra sobre o esvaziamento populacional, o abandono de casarões coloniais, a pobreza e a inércia urbanas no final do século XIX, o que lhe rendeu o escárnio de ser chamada Vila Pobre" (Villaschi, 2014, p. 68).

A categorização de cidade fracassada teria se mantido até 1930, como aponta Villaschi (2014), apesar da visibilidade que os modernistas deram ao seu patrimônio na década de 1920, que culminou em ações mais efetivas como a criação da Inspetoria de Monumentos e Sítios em 1933. Assim, o processo de valorização da cidade pelo seu valor histórico teve resultados mais efetivos a partir desse momento, quando se vislumbrou a possibilidade de fazer de Ouro Preto a cidade símbolo do passado colonial e do barroco mineiro.

Tem-se aí um novo marco para a história da cidade, quando há uma mudança nos valores atribuídos à estrutura urbana da antiga cidade colonial, a princípio vinculado aos seus bens culturais, símbolos do passado dispostos ao longo da malha urbana e em seguida ao conjunto urbano como um todo. Nesse momento é importante compreender que os valores estavam ligados muito mais aos aspectos artísticos do que aos históricos, e muito mais à soma dos elementos artísticos no espaço urbano do que propriamente à dinâmica e compreensão do espaço como um todo. Isso pode ser demonstrado pelo texto do Decreto $\mathrm{n}^{\mathrm{o}}$ 22.928 de 12 de julho de 1933, que erigiu a cidade de Ouro Preto em Monumento Nacional, que diz: 
Considerando que é dever do Poder Público defender o patrimônio artístico da Nação e que fazem parte das tradições de um povo os lugares em que se realizaram os grandes feitos da sua história;

Considerando que a cidade de Ouro Preto, antiga capital do Estado de Minas Gerais, foi teatro de acontecimentos de alto relevo histórico na formação da nossa nacionalidade e que possue (sic) velhos monumentos, edifícios e templos de arquitetura colonial, verdadeiras obras d'arte, que merecem defesa e conservação (Ministério da Educação e Saúde do Brasil, Decreto 22.928/1933).

Destaca-se, nesse trecho do decreto, os seguintes termos: patrimônio artístico, monumentos, arquitetura colonial e obras d'arte. Todos esses traduzem os valores da cidade naquele momento e justificaram o seu reconhecimento como cidade monumento, pelo seu aspecto vinculado aos feitos artísticos na arquitetura e nos monumentos dispostos na cidade. $\mathrm{Ou}$, ainda, pelos valores do tombamento realizado em 1938, do conjunto arquitetônico e urbanístico da cidade que foi inscrito somente no Livro do Tombo das Belas Artes, inscrição no 039. De acordo com o Instituto do Patrimônio Histórico e Artístico Nacional (IPHAN), o livro se refere aos valores artísticos, "às artes de caráter não utilitário, opostas às artes aplicadas e às artes decorativas. Para a História da Arte, imitam a beleza natural e são consideradas diferentes daquelas que combinam beleza e utilidade" (IPHAN, s/ $\mathrm{d}^{1}$ ). Esses valores são os mesmos atribuídos de modo geral às pinturas, esculturas, por exemplo, e vinculados à nobreza, de acordo com a História da Arte.

Nesse sentido, o reconhecimento dos valores da cidade monumento na década de 1930, ainda embrionários no Brasil em termos de políticas de patrimônio, não levavam em consideração a totalidade do conjunto, mas os monumentos e as artes pelas características da arquitetura colonial e o barroco mineiro, como foi denominado. Se identifica aí um paradoxo, apesar do tombamento ser referente ao conjunto arquitetônico e urbanístico, os valores destacados referiam-se a bens culturais isolados que se traduziam num certo padrão ao longo da cidade.

Todas essas questões de transição da cidade velha/decadente para a cidade histórica/monumento se dão no contexto da publicação de Holanda de 1936, o que corrobora com a sua narrativa como a concretização do senso comum em ciência, tal como foi exposto no começo desse estudo. A urbanização da cidade ainda não integrava os valores que se encontram nas publicações recentes, ou seja, a cidade continuava sendo vinculada à desordem espacial, ruas mal feitas e, portanto, refletindo a ideia de que o planejamento estava vinculado a simetrias e formas bem definidas como as colônias da América espanhola.

Somente em 1986 a cidade foi tombada pelo IPHAN com registro no Livro Histórico (inscrição no 512) e no Livro Arqueológico, Etnográfico e Paisagístico (inscrição no 098), o que demonstra uma ampliação dos valores atribuídos à cidade. Isso porque a própria descrição dos livros demonstra a valorização da dinâmica da cidade, e a totalidade de suas manifestações culturais. No Livro do Tombo Histórico, o IPHAN envolve "os bens culturais em função do seu valor histórico que se dividem em bens imóveis (edificações, fazendas, marcos, chafarizes, pontes, centros históricos, por exemplo) e móveis (imagens, mobiliário, quadros e xilogravuras, entre outras peças)" (IPHAN, s/d), ou seja, os bens de interesse vinculados à memória do país; e o Livro do Tombo Arqueológico, Etnográfico e Paisagístico em que sobressai a seguinte frase "cidades ou conjuntos arquitetônicos que se destaquem por sua relação com o território onde estão implantados" (IPHAN, s/d). Soma-se a essas descrições a informação de no 110/86 emitida pela Diretoria de Tombamento e Conservação do SPHAN, sugerindo a inserção da cidade nesses Livros do Tombo e ainda a definição da paisagem envoltória do conjunto com base na Carta de Veneza, recomendação internacional para abrangência da paisagem.

A inscrição foi realizada, apenas, no Livro das Belas Artes. No entanto, entende-se hoje, que um conjunto urbano constitui, mais do que um bem de valor artístico, um acervo que representa uma paisagem urbana e, mesmo, se integra forçosamente à paisagem natural na qual está inserida. A Carta

\footnotetext{
${ }^{1}$ Recuperado em 01 de setembro de 2020, de http://portal.iphan.gov.br/pagina/detalhes/608.
} 
de Veneza, de 1964 é enfática, quando diz que 'a conservação de um monumento implica a de uma moldura à sua escala'. Assim, a paisagem natural e aquela agenciada pelo homem, que formam a moldura natural do núcleo urbano de Ouro Preto, deverão ser motivo de preservação necessária à garantia da integridade do conjunto arquitetônico e urbanístico tombado (SPHAN, Informação $\mathrm{n}^{\mathrm{o}}$ 110/1986).

Como se lê no documento, os valores atribuídos à cidade se transformam e se tornam mais abrangentes, destacando-se os termos: paisagem urbana, paisagem natural, homem, moldura natural, núcleo urbano, integridade. Tais valores modificam significativamente a relação da cidade com o conjunto a partir de novas medidas para a sua conservação, mais uma vez embrionárias no Brasil.

Não se pode afirmar, pelos limites desse estudo, que as narrativas que começaram a discutir e contradizer a percepção de Holanda tenham influenciado essa abertura, no entanto, pode-se entender que o surgimento desses novos discursos acerca da malha urbana das antigas cidades coloniais brasileiras, como a valorização do conjunto de forma mais complexa, traduzem as perspectivas do momento, ampliando valores e possibilitando novos olhares para o passado.

\section{Considerações finais}

Quando se trata de planejamento urbano das antigas vilas e cidades brasileiras, cujas construções se deram no período colonial, é possível identificar na bibliografia da História e do Urbanismo ao menos duas narrativas mais comuns, conforme exposto, no século XX: uma delas vinculada a Holanda e a outra a autores contemporâneos como Delson. De um lado, a ideia de cidades não planejadas parece ter suas bases no senso comum, na concretização de uma ideia popular pela ciência; após um percurso epistemológico, de conhecimento da historicidade das tradições urbanas portuguesas (que contrapôs o senso comum à ciência) observou-se uma ruptura que culminou em novas percepções da ciência sobre o planejamento urbano do período colonial. E, assim, de outro lado, se encontra uma outra narrativa que busca confrontar o senso comum e sobrepor a questão do planejamento com diferentes perspectivas para essas antigas cidades.

Entre a ruptura e a construção, propostos por Santos, o que se observa pelos registros e pela bibliografia é que ambas narrativas se relacionam com os valores envolvidos de cada período em que foram abordadas e que esse seria um momento de reencontro, em que diferentes pontos de vista podem ser apresentados e contextualizados para que, juntos, construam uma nova epistemologia da História do Urbanismo no Brasil e para a História das antigas cidades brasileiras.

Para além das questões de morfologia urbana, observa-se uma abertura ao conhecimento de outras abordagens, incorporando-se, nessas leituras, a sociologia, a psicologia, a arte, dentre várias outras possibilidades que levam à compreensão das relações com o espaço urbano. Enxergar o passado com outros vieses permite compreender as dinâmicas do presente e a busca por melhores condições de vivência no futuro, prezando pela sustentabilidade.

A fundação das cidades brasileiras seguiu tradições urbanas portuguesas com diferentes variáveis, e que, aos poucos, estão sendo reveladas pelas pesquisas. Nesse ponto, a interdisciplinaridade favorece e torna possível tais revelações. Cidades como Olinda e Salvador, com um traçado mais comumente associado, ao que se considera planejado, e Mariana e Ouro Preto, com uma organização do espaço pensada no contexto de domínio social e poder harmonizados com o relevo e os desníveis, se traduzem em dois exemplos icônicos para essas narrativas.

No caso de Ouro Preto, os marcos históricos da cidade no século XX coincidem com os períodos em que se incorporam as duas diferentes narrativas acerca de seu espaço urbano. 0 que se vê através das fontes apresentadas são valores que, considerados no ápice da gestão de todo o seu patrimônio por órgãos federais, traduzem o pensamento coletivo daqueles contextos e permitem uma visão do passado mais respeitosa, minimizando a possibilidade de anacronismo.

Espera-se com esse estudo instigar as discussões acerca da História do Urbanismo de cidades como essas, para novos olhares e novos apontamentos cada vez mais relacionados com as diversas áreas do 
conhecimento que possam estar envolvidas. E assim, que novas constatações sejam feitas, favorecendo a interpretação do passado sob diferentes olhares contemporâneos.

\section{Referências}

\section{Fontes}

Constituições Primeiras do Arcebispado da Bahia (1853), feytas, e ordenada pelo... Senhor d. Sebastião Monteyro da Vide...propostas, e aceytas em o Synodo Diocesano, que o dito Senhor celebrou em 12 de junho de 1707. São Paulo: Typographia 2 de Dezembro. Recuperado em 01 de setembro de 2020, de <https://www2.senado.leg.br/bdsf/handle/id/222291>.

Instituto do Patrimônio Histórico e Artístico Nacional (1938). Livro das Belas Artes. Inscrição noo 039 de 20-4-1938, № Processo 0070-T-38. Dispõe sobre o tombamento do conjunto arquitetônico e urbanístico de Ouro Preto.

Instituto do Patrimônio Histórico e Artístico Nacional (1986). Livro Histórico. Inscrição no 512 de 15-9-1986, № Processo 0070-T-38. Dispõe sobre o tombamento do conjunto arquitetônico e urbanístico de Ouro Preto.

Instituto do Patrimônio Histórico e Artístico Nacional (1986). Livro Arqueológico, Etnográfico e Paisagístico. Inscrição no 098 de 15-9-1986, № Processo 0070-T-38. Dispõe sobre o tombamento do conjunto arquitetônico e urbanístico de Ouro Preto.

Ministério da Educação e Saúde do Brasil (1933). Decreto N. 22.928, de 12 de julho de 1933. Erige a cidade de Ouro Preto em monumento nacional. In: Acervo Digital do Instituto do Patrimônio Histórico e Artístico Nacional. Número do documento 0070-T-38. Recuperado em 10 de setembro de 2020, de

http://acervodigital.iphan.gov.br/xmlui/handle/123456789/4776?discover?rpp=10\&etal=0\&query=0UR0+PRET0\&filter type_ $0=$ format\&filter_relational_operator_ $0=$ equals\&filter_ $0=$ textual.

Serviço do Patrimônio Histórico e Artístico Nacional (1938). Informação No 110/86. Conjunto Arquitetônico e Urbanístico da cidade de Ouro Preto-MG. In: Acervo Digital do Instituto do Patrimônio Histórico e Artístico Nacional. Número do documento 0070-T-38. Recuperado em 2 de setembro de 2020, de http://acervodigital.iphan.gov.br/xmlui/handle/123456789/4776?discover?rpp=10\&etal=0\&query=0UR0+PRETO\&filter type_0=format\&filter_relational_operator_0=equals\&filter_0=textual.

\section{Bibliografia}

Bicalho, M. F. B. (1998). 0 urbanismo colonial e os símbolos do poder: o exemplo do Rio de Janeiro nos séculos XVII e XVIII. Estudos Ibero-Americanos, XXIV(1), 31-57. Recuperado em 5 de setembro de 2020, de http://revistaseletronicas.pucrs.br/ojs/index.php/iberoamericana/article/view/28196/15825.

Bourdieu, P. (1989). O poder simbólico. Tradução de Fernando Tomaz. Rio de Janeiro: Difusão Editorial.

Correia, J. (2020). Morfologia e Patrimônio Urbano: cidade colonial portuguesa versus cidade tradicional islâmica. Curso de férias da Universidade Estadual de Maringá, Programa de Pós-Graduação em Arquitetura e Urbanismo. Maringá, 2020.

Delson, R. M. (1997). Novas Vilas para Brasil-Colônia: planejamento espacial e social no século XVIII. Brasília: Editora ALVACIORD.

Fonseca, A., Prado Filho, J. F. (2004). Controle e uso da água na Ouro Preto dos séculos XVIII e XIX. (Dissertação de Mestrado). Programa de pós-graduação em Engenharia Ambiental da Universidade Federal de Ouro Preto, Ouro Preto.

Holanda, S. B. (1995). Raízes do Brasil. (26.ed.). São Paulo: Companhia das Letras.

Instituto do Patrimônio Histórico e Artístico Nacional. (s/d). Livros do Tombo. Recuperado em 1 de setembro de 2020, de http://portal.iphan.gov.br/pagina/detalhes/608.

Moreau, F. E. (2011). Arquitetura militar em Salvador da Bahia - século XVI a XVII. (Tese de Doutorado). Universidade de São Paulo, Faculdade de Arquitetura e Urbanismo. São Paulo.

Natal, C. M. (2007). Ouro Preto: a construção de uma cidade histórica, 1891-1933. (Dissertação de Mestrado). Departamento de História do Instituto de Filosofia e Ciências Humanas da Universidade Estadual de Campinas, Campinas. Campinhas. 
Pereira, A. L. T. (2000). Arquitetura, urbanismo e topografia em Ouro Preto no século XVIII. (Dissertação de Mestrado). Departamento de História do Instituto de Filosofia e Ciências Humanas. Campinas.

Salgado, M. (2010). Ouro Preto: paisagem em transformação. (Dissertação de Mestrado). Universidade Federal de Minas Gerais, Faculdade de Arquitetura e Urbanismo. Belo Horizonte.

SANTOS, B. de S. (1989). Ciência e senso comum. In Santos, B. de S. Introdução a uma ciência pós-moderna (p. 33-49). Porto: Edições Afrontamento.

Smith, R. C. (2012). Robert Smith e o Brasil: arquitetura e urbanismo. In Reis Filho, N. G. (Org.). IPHAN. (vol. 1). Brasília.

Villaschi, J. N. S. (2014). Hermenêutica do patrimônio e apropriação do território em Ouro Preto - MG. (Tese de Doutorado). Faculdade de Filosofia, Letras e Ciências Humanas, Universidade de São Paulo, São Paulo. Recuperado em 1 de setembro de 2020, de doi:10.11606/T.8.2014.tde-07112014-184004.

Editor: Rodrigo Firmino

Recebido: 02 dez. 2020

Aprovado: 17 mar. 2021 